\title{
ALTERNATIVAS PARA ADUBAÇÃO DE PORTA-ENXERTOS DE ABACATEIRO 'QUINTAL' E SEU EFEITO NO PEGAMENTO DE ENXERTIA ${ }^{1}$
}

\author{
ANA CLAUDIA COSTA ${ }^{2}$, ANTÔNIO DECARLOS NETO 3 , \\ JOSÉ DARLAN RAMOS ${ }^{4}$, DANIELLA INES BORGES ${ }^{2}$
}

RESUMO - O abacate é uma fruta de alta expressividade no cenário frutícola brasileiro. Dos fatores limitantes na expansão racional dessa frutífera, destaca-se a dificuldade de obtenção de mudas de alta qualidade. O objetivo deste trabalho foi avaliar a obtenção de porta-enxertos de abacateiro 'Quintal', em condições de telado, com o uso de fertilizante de liberação lenta e solução nutritiva, com diferentes doses de N, P e K. O experimento foi instalado e conduzido no Setor de Fruticultura do Departamento de Agricultura da Universidade Federal de Lavras-MG, de maio a outubro de 2009. O delineamento utilizado foi em blocos casualizados, em esquema fatorial $2 \mathrm{X} 4$ (duas fontes de fertilizantes e quatro doses) com um tratamento adicional (controle), com quatro repetições, sendo a parcela experimental composta de dez plantas. Os tratamentos consistiram em quatro doses de fertilizante de liberação lenta 15-10-10 ( $\left.\mathrm{N}_{-} \mathrm{P}_{2} \mathrm{O}_{5}-\mathrm{K}_{2} \mathrm{O}\right)$, nas dosagens 4; 8; 16 e $24 \mathrm{~kg}$ $\mathrm{m}^{-3}$ de solo usado como substrato e quatro doses de solução nutritiva, sendo o NPK aplicado numa mistura de ureia, nitrato de potássio e monoamônio fosfato, na mesma proporção do outro fertilizante. As plantas foram enxertadas, utilizando-se como copa da cultivar Fortuna. As características do porta-enxerto avaliadas foram: altura $(\mathrm{cm})$, diâmetro $(\mathrm{mm})$, matéria seca das folhas, raízes e caule $(\mathrm{g})$, teor de $\mathrm{N}, \mathrm{P}$ e K nas folhas $\left(\mathrm{mg} \mathrm{kg}^{-1}\right)$ e porcentagem de pegamento da enxertia (\%). Houve interação significativa entre os fatores para a altura, diâmetro, matéria seca das folhas, raízes, caule e porcentagem de pegamento da enxertia. $\mathrm{O}$ uso de fertilizante de liberação lenta propiciou maior crescimento e desenvolvimento dos porta-enxertos de abacateiro cultivar Quintal comparado à solução nutritiva. Doses acima de $4 \mathrm{~kg} \mathrm{~m}^{-3}$ de fertilizante de liberação lenta e solução nutritiva não produziram efeito positivo na formação de porta-enxertos de abacateiro 'Quintal'. Termos para indexação: Persea americana; 'Fortuna'; nutrição; propagação.

\section{FERTILIZATION ALTERNATIVES FOR ‘QUINTAL’AVOCADO SEEDLINGS}

ABSTRACT - The avocado is a fruit of high expression in Brazilian fruit scenario. One of the factors that limit the rational expansion of this fruit in Brazil is the difficulty of obtaining high quality seedlings. This study aimed to-evaluate the formation of Quintal avocado rootstocks, under greenhouse conditions, with use of slow-release fertilizer and nutrient solution with different doses of NPK. The experiment was carried out at the Division Fruit Crops of the Department of Agriculture/Universidade Federal de Lavras-MG, from May to October 2009. The experimental design was in randomized blocks in factorial scheme $2 \mathrm{X} 4$ (two sources and four doses of fertilizers) with an additional treatment (control) with four replicates, and the experimental plot was constituted by ten plants. Plants were grafted, using cultivar Fortuna as scion. Treatments were consisted by four doses of slow-release fertilizer 15-10-10 (NPK) at a ratio of 4, 8, 16 and $24 \mathrm{~kg} \mathrm{~m}^{-3}$ of soil used as substrate, and four doses of nutrient solution, where NPK was applied in a mixture of urea, potassium nitrate, and phosphate monoammonium in the same proportion as the other fertilizer. The rootstock characteristics evaluated were: height $(\mathrm{cm})$, diameter $(\mathrm{mm})$, dry leaves, roots and stems $(\mathrm{g})$, $\mathrm{N}, \mathrm{P}$ and $\mathrm{K}$ in leaves $\left(\mathrm{mg} \mathrm{kg}^{1}\right)$ and grafting success rate (\%). It was noticed a significant interaction among factors for height, diameter, leaves, roots and stems dry, and grafting success rate characteristics. The use of slow-release fertilizer promoted greater growth and development of Quintal cultivar avocado seedlings when compared to nutrient solution. Doses above $8 \mathrm{~kg} \mathrm{~m}^{-3}$ of slow-release fertilizer and nutrient solution were not satisfactory in the formation of 'Quintal' avocado seedlings.

Index Terms: Persea americana; 'Fortuna'; nutrition; propagation.

\footnotetext{
'(Trabalho 209-10). Recebido em: 07-10-2010. Aceito para publicação em: 23-09-2011.

${ }^{2}$ Eng. Agrônomas, Doutorandas do Curso de Fitotecnia da Universidade Federal de Lavras (UFLA). Rua Sílvio Menicucci, 403, Centro, CEP: 37200-000, Lavras-MG. E mails: aninhamel@gmail.com; dinesborges@yahoo.com.br.

${ }^{3}$ Eng. Agrônomo, Dr. Prof. do Departamento de Agricultura, Universidade Federal de Lavras (UFLA). C. P. 3037, CEP: 37200-000, Lavras-MG. Email: adecarlos@pop.com.br.

${ }^{4}$ Eng. Agrônomo, Dr. Prof. do Departamento de Agricultura, Universidade Federal de Lavras (UFLA). C. P. 3037, CEP: 37200-000, Lavras-MG. Email: darlan@ufla.br. Bolsista de produtividade em Pesquisa do CNPq.
} 


\section{INTRODUÇÃO}

O abacateiro tem grande expressão econômica no Brasil (OLIVEIRA et al., 2008), ocupando a quinta posição na produção mundial, com 166 mil toneladas em 10,55 mil hectares cultivados. O maior produtor mundial de abacates é o México, seguido pelo Chile, República Dominicana, Colômbia e Brasil (FAO, 2010). O Estado de São Paulo destaca-se como maior produtor, seguido por Minas Gerais, Paraná e Rio Grande do Sul. Minas Gerais produziu 33 mil toneladas, em área colhida de 2,3 mil hectares em 2008 (AGRIANUAL, 2010).

Sua adaptabilidade ao solo e ao clima brasileiros, aliada à extensão territorial, dá ao cultivo do abacateiro perspectiva de grande expansão. Até o momento, um dos fatores que mais limitam o crescimento racional dessa frutífera é a dificuldade de obtenção de mudas notadamente de alta qualidade, sendo que muitos viveiristas ainda não utilizam técnicas de propagação assexuada, prevalecendo a sexuada.

No processo de produção da muda assexuada de abacateiro de alta qualidade, destaca-se a fase de obtenção do porta-enxerto, compreendida entre a semeadura e o momento da enxertia (ALMEIDA; SAMPAIO, 2008). Esta fase caracteriza-se por um rápido crescimento vegetativo e alta exigência nutricional do porta-enxerto.

Embora o abacateiro seja cultivado na maioria das regiões tropicais e subtropicais do mundo, são poucas as informações sobre sua nutrição mineral no processo de formação de mudas.

A produção de mudas em ambiente protegido, mesmo sendo um sistema eficiente, requer a utilização de recipientes com dimensões limitadas, e o longo período de permanência dessas plantas nesses recipientes torna o sistema radicular sujeito a restrições físicas, tornando também os substratos suscetíveis a perdas de nutrientes por lixiviação, sendo a adubação fator decisivo para o bom desenvolvimento das mudas (BRACHTVOGEL; MALAVASI, 2010).

A utilização de fertilizantes de liberação lenta na mistura com substratos pode contribuir para a otimização dos resultados na produção de mudas de espécies frutíferas, tanto do ponto de vista econômico como ambiental. Esses fertilizantes, em geral, são constituídos pelo capeamento de adubos solúveis em água, com polímeros formando grânulos (PEREIRA et al., 2000). Pelo fato de permitirem a disponibilidade contínua de $\mathrm{N}$ para as mudas, durante maior tempo, existe menor possibilidade de ocorrer deficiência desse nutriente durante o período de formação das mudas, o que dispensaria aplicações parceladas reduzindo, assim, os custos operacionais na formação da muda (MENDONÇA et al., 2007).

O parcelamento da adubação via solução nutritiva, que pode ser definida como um sistema homogêneo, onde os nutrientes necessários às plantas estão dispersos, geralmente na forma iônica e em proporções adequadas (COMETTI et al., 2006), também pode ser uma alternativa para melhorar a eficiência das adubações. Dessa forma, as perdas por lixiviação e volatilização poderão ser menores do que quando se aplicam os adubos incorporados ao substrato.

Este trabalho teve como objetivo avaliar a obtenção de porta-enxertos de abacateiro 'Quintal', em condições de telado, com o uso de fertilizante de liberação lenta e solução nutritiva, com diferentes doses de N, P e K.

\section{MATERIAL E MÉTODOS}

O experimento foi instalado e conduzido no Setor de Fruticultura do Departamento de Agricultura da Universidade Federal de Lavras, Minas Gerais, no período de maio a outubro de 2009.

Foram utilizadas sementes de frutos de abacateiro cultivar 'Quintal', que foram colhidos numa área comercial no Município de Carmo da Cachoeira - MG. As sementes foram extraídas e selecionadas quanto ao tamanho (médio) e ao aspecto fitossanitário. Em seguida, foi realizado o corte de um terço da porção apical das sementes, e essas foram plantadas em sacos de polietileno com $4 \mathrm{dm}^{3}$ de capacidade, sendo mantidas sobre bancadas de madeira em telado de cobertura plástica, com temperatura variando entre 8 e $31^{\circ} \mathrm{C}$, e umidade relativa de 40 a $95 \%$.

O solo utilizado como substrato foi classificado como Latossolo Vermelho distroférrico (EMBRAPA, 1999), sendo analisado para determinação de suas características químicas (Tabela 1) (CFSEMG, 1999). Nele, foram aplicados os tratamentos, que consistiram em quatro doses de fertilizante de liberação lenta 15-10-10 (N- $\left.\mathrm{P}_{2} \mathrm{O}_{5}-\mathrm{K}_{2} \mathrm{O}\right)$, nas dosagens $4 ; 8 ; 16$ e $24 \mathrm{~kg} \mathrm{~m}^{-3}$ de substrato (Tabela 2); e quatro doses de solução nutritiva, em que NPK foi aplicado numa mistura de ureia $(44 \% \mathrm{~N})$, nitrato de potássio $\left(44 \% \mathrm{~K}_{2} \mathrm{O} ; 13 \% \mathrm{~N}\right)$ e monoamônio fosfato $(44 \%$ $\mathrm{P}_{2} \mathrm{O}_{5} ; 11 \%$ de N) (Tabela 2), na mesma proporção do fertilizante de liberação lenta. O controle consistiu na ausência de adubação. Os adubos aplicados via solução nutritiva foram diluídos em água, sendo realizados cálculos através de regra de três simples, para se aplicar as mesmas quantidades de N, P e K nas duas fontes de adubação utilizadas.

A solução nutritiva foi parcelada em 20 aplicações, sendo a frequência estabelecida de três 
em três dias, a partir de 30 dias após a germinação das sementes. A adubação foi feita vaso a vaso, com o auxílio de um medidor, e foram aplicados $50 \mathrm{~mL}$ por planta.

O delineamento utilizado foi em blocos casualizados, em esquema fatorial $2 \mathrm{X} 4$ (duas fontes de fertilizantes e quatro doses), com um tratamento adicional (controle), totalizando nove tratamentos, com quatro repetições, sendo a parcela experimental composta de dez plantas.

Os tratos culturais utilizados foram a irrigação, feita diariamente, utilizando-se de regador manual e controlando-se a quantidade de água para evitar perdas por lixiviação, controle de pragas e doenças, e a retirada manual das plantas daninhas.

Após 150 dias do plantio, metade das plantas de todas as parcelas (cinco plantas por parcela) foi retirada para ser analisada, e a outra metade foi enxertada. As plantas foram enxertadas, utilizandose como copa a cultivar Fortuna. Empregou-se o processo de enxertia de garfagem de topo em fenda cheia (ALMEIDA; SAMPAIO, 2008).

As características do porta-enxerto avaliadas foram: altura da planta $(\mathrm{cm})$, medida a partir do colo até a gema apical; diâmetro do caule (mm), medido a $2 \mathrm{~cm}$ do colo; matéria seca das folhas, raízes e caule (g); teor de N, P e K nas folhas ( $\left.\mathrm{mg} \mathrm{kg}^{-1}\right)$, e porcentagem de pegamento da enxertia (\%), um mês após a realização dessa.

Separaram-se, com o auxílio de uma tesoura, as folhas, caule e raízes. Posteriormente, as partes foram colocadas em estufa, à temperatura de $65^{\circ} \mathrm{C}$, até atingirem peso constante. Após isso, foram efetuadas as pesagens, obtendo-se assim a matéria seca de cada parte.

Para a determinação do teor de N, P e K, foi feita amostragem foliar, utilizando-se de todas as folhas das cinco plantas analisadas por parcela. Após a secagem, as folhas foram trituradas, e os teores de $\mathrm{N}$ foram quantificados, utilizando-se do extrato da digestão sulfúrica. A partir do extrato obtido da digestão nitroperclórica, foram determinados os teores de $\mathrm{P}$ e K. Os métodos adotados para a determinação dos teores dos nutrientes estão descritos em Malavolta et al. (1997).

Foi utilizado o pacote ExpDes do programa $\mathrm{R}$ para realizar as análises estatísticas (CAVALCANTI, 2010). Os dados foram submetidos à análise de variância e à análise de regressão, pois os tratamentos do fator doses de fertilizante são de natureza quantitativa. A comparação dos dois tipos de fertilizantes foi feita pelo teste de $\mathrm{F}$ da análise de variância, e a comparação do controle (ausência de adubação) com os demais tratamentos (que receberam algum tipo de adubação) foi feita por contraste de médias.

\section{RESULTADOS E DISCUSSÃO}

Observando-se a Tabela 3, verifica-se que a altura dos porta-enxertos, diâmetro do caule, matéria seca das folhas, raízes e caule, e a porcentagem de pegamento da enxertia apresentaram diferenças significativas, tanto para os efeitos de Adubo (A) e Dose (D), quanto para interação (A*D). Para os teores de N e K, não foi observado efeito significativo de fontes diferentes nem de doses dessas fontes. Enquanto para o teor de $\mathrm{P}$, não houve efeito significativo da interação entre os fatores fontes de fertilizante e doses, mas houve efeito significativo dos fatores principais. Portanto, o teor de P nas folhas varia com a dose empregada e com o tipo de fertilizante utilizado, sendo que a solução nutritiva promoveu maior acúmulo de P nas folhas em relação ao fertilizante de liberação lenta (Tabela 4) e houve aumento do teor de $\mathrm{P}$ nas folhas, conforme aumentaram as doses de fertilizantes utilizadas (Figura 6).

Ao desdobrar o fator adubo dentro do fator doses (Tabela 4), verifica-se que o fertilizante de liberação lenta superou a solução nutritiva nas doses 4; $8 ; 16$ e $24 \mathrm{~kg} \mathrm{~m}^{-3}$ para as características altura, diâmetro, matéria seca das folhas e matéria seca do caule, sendo que, na dose $4 \mathrm{~kg} \mathrm{~m}^{-3}$, não houve diferença entre os fertilizantes. Com relação ao diâmetro do caule e da matéria seca do caule, o fertilizante de liberação lenta teve melhor desempenho que a solução nutritiva apenas nas doses 16 e $24 \mathrm{~kg} \mathrm{~m}^{-3}$, nas doses 4 e $8 \mathrm{~kg} \mathrm{~m}^{-3}$ não houve diferença significativa entre os fertilizantes utilizados. Para a matéria seca das raízes, o fertilizante de liberação lenta superou a solução nutritiva nas doses $8 ; 16$ e $24 \mathrm{~kg} \mathrm{~m}^{-3}$. A porcentagem de pegamento da enxertia foi maior quando se utilizou o fertilizante de liberação lenta em relação à solução nutritiva, nas doses $4 ; 16 \mathrm{e}$ $24 \mathrm{~kg} \mathrm{~m}^{-3}$. O teor de P nas folhas foi maior quando se utilizou solução nutritiva em todas as doses empregadas. E para os teores de $\mathrm{N}$ e $\mathrm{K}$ nas folhas, não houve influência significativa do tipo de fertilizante.

Analisando a característica altura de portaenxertos (Figura 1), observa-se que o aumento das doses de fertilizante de liberação lenta e solução nutritiva não favoreceu o crescimento dos portaenxertos. A dose que promove a menor altura é 19,01 $\mathrm{kg} \mathrm{m}^{-3}$ do fertilizante de liberação lenta, que resulta em altura mínima de $32 \mathrm{~cm}$. Nos porta-enxertos adubados com solução nutritiva, a dose que resultou na altura mínima de $16,47 \mathrm{~cm}$ é $21,02 \mathrm{~kg} \mathrm{~m}^{-3}$. Para promover maior altura das plantas, a utilização de $4 \mathrm{~kg} \mathrm{~m}^{-3}$ de qualquer um dos fertilizantes seria o 
recomendável, já que, para essa dose, não houve diferença significativa entre os dois adubos.

Em relação ao diâmetro do caule (Figura 2), verifica-se redução linear com o aumento das doses de fertilizante de liberação lenta. Os portaenxertos adubados com a menor dose $\left(4 \mathrm{~kg} \mathrm{~m}^{-3}\right)$ de fertilizante de liberação lenta apresentaram incremento de $20,49 \%$ no diâmetro em relação às mudas adubadas com a maior dose $\left(24 \mathrm{~kg} \mathrm{~m}^{-3}\right)$. Para os porta-enxertos adubados com solução nutritiva, a dose que proporcionou o menor diâmetro do caule foi $28,50 \mathrm{~kg} \mathrm{~m}^{-3}$, com a qual se obtém diâmetro mínimo de $5,39 \mathrm{~mm}$. Portanto, para promover maior diâmetro do caule, seria preferível o uso de $4 \mathrm{~kg} \mathrm{~m}^{-3}$ de qualquer um dos adubos, já que não foi observada diferença significativa entre os dois fertilizantes, na dose $4 \mathrm{~kg} \mathrm{~m}^{-3}$.

Os resultados obtidos para a altura e diâmetro podem ser atribuídos à elevada reserva de nutrientes presentes na semente do abacateiro, o que, possivelmente, faz com que ele necessite de menor quantidade de adubo para a formação dos porta-enxertos. De acordo com Silva et al. (1980), a semente de abacate apresenta a seguinte composição: $1,21 \%$ de $\mathrm{N} ; 0,13 \%$ de $\mathrm{P} ; 1,26 \%$ de $\mathrm{K} ; 0,04 \%$ de $\mathrm{Ca} ; 0,02 \%$ de $\mathrm{Mg} ; 0,10 \%$ de $\mathrm{S} ; 12$ ppm de $\mathrm{B} ; 43$ ppm de Fe; 13 ppm de $\mathrm{Cu} ; 9$ ppm de $\mathrm{Mn} ; 15$ ppm de Zn; 0,09 ppm de Mo.

Além disso, é provável que as maiores doses de adubação utilizadas $\left(16\right.$ e $\left.24 \mathrm{~kg} \mathrm{~m}^{-3}\right)$, dos dois tipos de adubos, tenham disponibilizado excesso de nutrientes para as plantas, o que prejudicou seus crescimentos. Embora o fertilizante de liberação lenta possua período de liberação em torno de quatro a seis meses, a alta temperatura do telado onde foi conduzido o experimento, pode ter disponibilizado rapidamente os nutrientes.

Mendonça et al. (2008), trabalhando com a formação de mudas de tamarindeiro, verificaram que a dose de $5,17 \mathrm{~kg} \mathrm{~m}^{-3}$ de fertilizante de liberação lenta 15-10-10 $\left(\mathrm{N}_{-} \mathrm{P}_{2} \mathrm{O}_{5}-\mathrm{K}_{2} \mathrm{O}\right)$ proporcionou maior altura de planta. Em trabalho realizado por Serrano et al. (2010), as doses do adubo de liberação lenta, fórmula 13-06-16 $\left(\mathrm{N}-\mathrm{P}_{2} \mathrm{O}_{5}-\mathrm{K}_{2} \mathrm{O}\right)$, que proporcionaram a maior altura das mudas de mamoeiro, foram 11,2 $\mathrm{kg} \mathrm{m}^{-3}$ para o 'Golden'; 7,7 $\mathrm{kg} \mathrm{m}^{-3}$ para o 'Calimosa'; 10,5 $\mathrm{kg} \mathrm{m}^{-3}$ para o 'INCAPER 09'; $11,6 \mathrm{~kg} \mathrm{~m}^{-3}$ para o 'Tainung 01', e 11,0 $\mathrm{kg} \mathrm{m}^{-3}$ para o 'INCAPER 39'. Já para o diâmetro do caule, Mendonça et al. (2007) observaram que o maior diâmetro $(5,51 \mathrm{~mm})$ das mudas do maracujazeiro foi obtido na dose $3,60 \mathrm{~kg} \mathrm{~m}^{-3}$ do fertilizante de liberação lenta (15-10-10).

As características matéria seca das folhas e matéria seca do caule comportaram-se de forma semelhante, pois ambas não apresentaram acréscimos com os aumentos das doses de adubos (Figuras $3 \mathrm{e}$ 4).

Os porta-enxertos adubados com fertilizante de liberação lenta na dose $4 \mathrm{~kg} \mathrm{~m}^{-3}$ apresentaram incremento de $33,68 \%$ na matéria seca das folhas em relação aos porta-enxertos adubados com a maior dose $\left(24 \mathrm{~kg} \mathrm{~m}^{-3}\right)$. Para os porta-enxertos adubados com solução nutritiva, a menor quantidade de matéria seca das folhas foi obtida na dose $27,40 \mathrm{~kg} \mathrm{~m}^{-3}$, com peso mínimo de 9,60 g. Portanto, a dose $4 \mathrm{~kg} \mathrm{~m}^{-3}$ de qualquer um dos adubos foi a que proporcionou maior quantidade de matéria seca das folhas.

Com relação à matéria seca do caule, os portaenxertos adubados com a menor dose $\left(4 \mathrm{~kg} \mathrm{~m}^{-3}\right)$ de fertilizante de liberação lenta apresentaram aumento de $44,74 \%$ em relação aos adubados com a maior dose $\left(24 \mathrm{~kg} \mathrm{~m}^{-3}\right)$, enquanto para os porta-enxertos adubados com solução nutritiva, a diferença foi de $95,84 \%$. Deduz-se que, para obter maior matéria seca do caule, seria necessário utilizar a dose $4 \mathrm{~kg} \mathrm{~m}^{-3} \mathrm{de}$ qualquer um dos fertilizantes.

A alta reserva da semente do abacateiro, aliada ao excesso de nutrientes fornecidos às plantas quando se utilizaram as maiores doses de adubação, justificam, também, as curvas decrescentes encontradas para a matéria seca das folhas e do caule, pois é provável que as maiores doses tenham causado fitotoxidez. Esse excesso de nutrientes pode ter causado desequilíbrio nutricional nas plantas, visto que alguns nutrientes podem competir entre si pelo mesmo sítio de absorção.

Pereira et al. (2000), trabalhando com dois tipos de substratos e cinco doses de fertilizante de liberação lenta (17-07-12), além de dois tratamentos adicionais que consistiam em: solução nutritiva ( $1 \mathrm{~g}$ de sulfato de amônio $+1 \mathrm{~g}$ de superfosfato simples $+0,5 \mathrm{~g}$ de cloreto de potássio por litro) aplicada semanalmente nas plantas; e uma adubação de NPK contendo $10 \mathrm{~g}$ de superfosfato simples $+6 \mathrm{~g}$ de cloreto de potássio $+2 \mathrm{~g}$ de ureia por $\mathrm{dm}^{-3}$, verificaram que a dose de $7,6 \mathrm{~kg} \mathrm{~m}^{-3}$ de fertilizante de liberação lenta proporcionou o maior peso de matéria seca da parte aérea de mudas de maracujazeiro-amarelo, e os tratamentos contendo fertilizante de liberação lenta superaram os demais tratamentos para a maioria das características analisadas.

Para a produção de mudas de angico-branco, Brondani et al. (2008) obtiveram que as doses 2,26 e $1,78 \mathrm{~kg} \mathrm{~m}^{-3}$ de fertilizante de liberação lenta (14-1414) proporcionaram as maiores taxas de matéria seca do caule e das folhas, respectivamente.

Os fertilizantes de liberação lenta apresentam 
diversas vantagens em relação à solução nutritiva na produção de porta-enxertos, pois eles podem reduzir consideravelmente os custos de produção, já que são incorporados uma única vez no substrato, ao contrário da solução nutritiva que é parcelada necessitando de mais mão de obra. Além disso, pelo fato de serem de liberação lenta, existe menor possibilidade de ocorrer deficiência nutricional nas plantas.

Para a característica matéria seca das raízes, verificou-se que houve interação entre tipo de adubação e doses (Tabela 3), indicando que os adubos influenciaram de modo diferente no acúmulo de matéria seca das raízes nas doses utilizadas. $\mathrm{O}$ aumento das doses de fertilizante de liberação lenta e solução nutritiva não foi favorável ao acúmulo de matéria seca nas raízes, cuja maior intensidade de massa ocorreu, em ambos os casos, na dose $4 \mathrm{~kg} \mathrm{~m}^{-3}$ (Tabela 4). A dose que promove menor quantidade de matéria seca das raízes é $32,12 \mathrm{~kg} \mathrm{~m}^{-3}$ do fertilizante de liberação lenta, que resulta em 40,10 g. Contudo, para os portaenxertos adubados com solução nutritiva, a dose que propicia menor quantidade de matéria seca das raízes é 21,04 $\mathrm{kg} \mathrm{m}^{-3}$ com a qual se obtém 4,88 g. Para obter maior valor de matéria seca das raízes, a preferência seria usar a dose $4 \mathrm{~kg} \mathrm{~m}^{-3}$ de qualquer um dos adubos.

Nomura et al. (2009), trabalhando com mudas de bananeira em diferentes substratos e com três tipos de fertilizantes, verificaram que o maior acúmulo de massa seca na raiz ocorreu em plantas que receberam fertilizante de liberação lenta, não havendo diferenças entre mudas cultivadas sem fertilizantes e com fertilizante de liberação normal.

$\mathrm{Na}$ Tabela 4, observa-se que os teores de $\mathrm{N}$ e K não foram influenciados pelo tipo de fertilizante, enquanto a solução nutritiva promoveu maior teor de $P$ nas folhas que o fertilizante de liberação lenta. $\mathrm{O}$ teor de $\mathrm{P}$ teve aumento linear com o aumento das doses de fertilizantes. Para cada unidade de aumento na dose de adubação, há um acréscimo de $0,0023 \mathrm{mg}$ $\mathrm{kg}^{-1}$ (Figura 6).

Esses resultados discordam dos encontrados por Pereira et al. (2000), que obtiveram teores significativamente maiores de macronutrientes na matéria seca de mudas de maracujazeiro adubadas com fertilizante de liberação lenta, quando comparados à adubação com solução nutritiva ou NPK.

Serrano et al. (2010) observaram que o aumento das doses do adubo de liberação lenta (1306-16) proporcionou aumentos lineares nos teores de $\mathrm{N}$ e K, em todos os genótipos de mamoeiro.

Com relação à porcentagem de pegamento da enxertia, verificou-se que houve interação significativa entre os fatores, tipo de adubação e doses, inferindo-se que os adubos utilizados influenciaram de modo diferente no pegamento da enxertia nas doses utilizadas. Na Tabela 4, verifica-se que o fertilizante de liberação lenta favoreceu maior porcentagem de pegamento da enxertia das mudas de abacateiro que a solução nutritiva nas doses 4; 16 e $24 \mathrm{~kg} \mathrm{~m}^{-3}$. Portanto, para se obter maior pegamento da enxertia, é preferível utilizar $4 \mathrm{~kg} \mathrm{~m}^{-3}$ de fertilizante de liberação lenta.

É importante salientar que os porta-enxertos adubados com 16 e $24 \mathrm{~kg} \mathrm{~m}^{-3}$ de solução nutritiva não apresentavam condições de serem enxertados, por isso a porcentagem de pegamento dessas plantas foi considerada zero.

Foram realizados contrastes de médias para comparar o controle (ausência de adubação) com os demais tratamentos (que receberam algum tipo de adubação). Os contrastes (Tabela 5) mostram que houve diferença significativa para quase todas as características estudadas, exceto para os teores de $\mathrm{N}, \mathrm{P}$ e K nas folhas. Esses resultados indicam que o controle teve melhor desempenho que os demais tratamentos utilizados no experimento, o que possivelmente ocorreu devido ao excesso de fertilizante aplicado já na dose mais baixa $\left(4 \mathrm{~kg} \mathrm{~m}^{-3}\right)$ e/ou pela ausência de doses inferiores a $4 \mathrm{~kg} \mathrm{~m}^{-3}$, a serem testadas. Além disso, verificou-se que foi possível a produção de porta-enxertos sem que fosse feita adubação. Isso, entretanto, não significa que não seja necessário adubar.

De maneira geral, o aumento das doses de fertilizante de liberação lenta e solução nutritiva acarretaram efeito prejudicial na formação de porta-enxertos de abacateiro, caracterizado como superdosagem de NPK. Este efeito depressivo pode ter ocorrido devido à diminuição do $\mathrm{pH}$ do substrato, através da liberação de $\mathrm{H}^{+}$produzidos durante o processo de nitrificação. Além disso, concentrações elevadas de potássio podem reduzir a absorção de cálcio e magnésio (PEREIRA et al., 2000).

Os resultados observados neste experimento sugerem que trabalhos futuros devam inserir em seus modelos experimentais doses menores que 4 $\mathrm{kg} \mathrm{m}^{-3}$ do fertilizante de liberação lenta (15-10-10) e solução nutritiva, incluindo a dose zero, visto que a dose ótima poderá ser obtida no intervalo de 0 (zero) a $4 \mathrm{~kg} \mathrm{~m}^{-3}$ de substrato. 
TABELA 1- Resultado da análise química do solo usado como substrato onde foi conduzido o experimento. Lavras-MG, 2009 (CFSEMG, 1999).

\begin{tabular}{|c|c|c|c|c|c|c|c|c|c|}
\hline $\mathrm{pH}$ & $\mathrm{Al}^{+3}$ & $\mathrm{H}+\mathrm{Al}^{+3}$ & $\mathrm{Mg}^{+2}$ & $\mathrm{Ca}^{+2}$ & SB & $\mathrm{T}$ & $\mathrm{t}$ & \multirow{2}{*}{\multicolumn{2}{|c|}{$\begin{array}{l}\text { M.O } \\
\text {-dag.kg-1 }\end{array}$}} \\
\hline $\mathrm{CaCl}_{2}$ & & & ----cm & $\mathrm{dm}^{3}-$ & & & . & & \\
\hline 6,4 & 0,0 & 1,3 & 0,2 & 3,5 & 3,8 & 5,1 & 3,8 & 1,4 & \\
\hline $\bar{P}$ & $\mathrm{~K}^{+}$ & $\mathrm{Zn}$ & B & $\mathrm{S}$ & $\mathrm{Cu}$ & $\mathrm{Fe}$ & $\mathrm{Mn}$ & $\mathrm{m}$ & $\mathrm{V}$ \\
\hline 3,0 & 57 & 1,1 & 0,1 & 15,6 & 3,0 & 30,0 & 21,17 & 0,0 & 74,5 \\
\hline
\end{tabular}

TABELA 2- Quantidade de $\mathrm{N}, \mathrm{P}_{2} \mathrm{O}_{5}$ e $\mathrm{K}_{2} \mathrm{O}$ oriundos dos componentes do fertilizante de liberação lenta e solução nutritiva, para as diferentes doses aplicadas no experimento. Lavras-MG, 2009.

\begin{tabular}{|c|c|c|c|c|c|c|c|c|c|}
\hline & \multicolumn{9}{|c|}{ DOSES APLICADAS $^{(\mathrm{a})}-$ (TRATAMENTOS): $^{2}$} \\
\hline \multirow[b]{2}{*}{ FONTES: } & \multicolumn{2}{|r|}{4} & \multicolumn{2}{|r|}{8} & \multicolumn{3}{|c|}{16} & \multicolumn{2}{|r|}{24} \\
\hline & $\mathrm{N}$ & $\mathrm{P}_{2} \mathrm{O}_{5} \mathrm{~K}_{2} \mathrm{O}$ & $\mathrm{N}$ & $\mathrm{P}_{2} \mathrm{O}_{5} \mathrm{~K}_{2} \mathrm{O}$ & $\mathrm{N}$ & $\mathrm{P}_{2} \mathrm{O}_{5}$ & $\mathrm{~K}_{2} \mathrm{O}$ & $\mathrm{N}$ & $\mathrm{P}_{2} \mathrm{O}_{5} \quad \mathrm{~K}_{2} \mathrm{O}$ \\
\hline
\end{tabular}

(g.m $\mathrm{m}^{-3}$ de substrato).

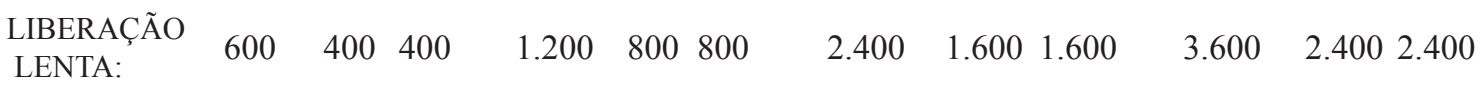

\section{SOLUÇÃO}

NUTRIT.:

\begin{tabular}{|c|c|c|c|c|c|c|c|c|c|c|c|c|}
\hline URÉIA & 381,816 & - & - & 763,632 & - & - & $1.527,264$ & - & - & $2.290,896$ & - & - \\
\hline $\mathrm{KNO}_{3}$ & 118,183 & _ & 400 & 236,366 & - & 800 & 472,732 & - & 1.600 & 709,098 & - & 2.400 \\
\hline MAP & 100,001 & 400 & - & 200,002 & 800 & - & 400,004 & 1.600 & - & 600,006 & 2.400 & \\
\hline TOTAL: & 600 & 400 & 400 & 1.200 & 800 & 800 & 2.400 & 1.600 & 1.600 & 3600 & 2.400 & 2.400 \\
\hline
\end{tabular}

(a): Doses aplicadas (kg.m ${ }^{-3}$ de substrato)

TABELA 3- Resumo da análise de variância para as características altura (H), diâmetro (D), porcentagem de pegamento da enxertia (PEG), matéria seca das folhas (MSF), matéria seca das raízes (MSR), matéria seca do caule (MSC), teor de nitrogênio $(\mathrm{N})$, fósforo $(\mathrm{P})$ e potássio $(\mathrm{K})$ das folhas de porta-enxertos de abacateiro cultivar Quintal, adubados com fertilizante de liberação lenta e solução nutritiva. Lavras-MG, 2009.

\begin{tabular}{lcccccccccc}
\hline $\begin{array}{c}\text { Fontes de } \\
\text { variação }\end{array}$ & GL & H & D & PEG & MSF & MSR & MSC & Q & P & K \\
\hline \multicolumn{1}{c}{} & 3 & 18,72 & 0,56 & 159,25 & 8,51 & 9,65 & 23,21 & 0,60 & 0,0015 & 0,22 \\
Bloco & 1 & $787,05^{* *}$ & $5,20^{* *}$ & $1.280,00^{* *}$ & $2.869,03^{* *}$ & $4.656,12^{* *}$ & $1.800,00^{* *}$ & $0,88^{\text {ns }}$ & $0,0098^{* *}$ & $0,09^{\text {ns }}$ \\
Adubo (A) & 1 & $477,30^{* *}$ & $11,51^{* *}$ & $1.100,00^{* *}$ & $2.152,28^{* *}$ & $3.891,75^{* *}$ & $3.491,70^{* *}$ & $0,28^{\text {ns }}$ & $0,0034^{*}$ & $0,12^{\text {ns }}$ \\
Dose (D) & 3 & $47,0^{* *}$ & Médios \\
A X D & 3 & $90,18^{* *}$ & $1,15^{*}$ & $2.700,00^{* *}$ & $384,44^{* *}$ & $646,20^{* *}$ & $537,25^{* *}$ & $0,01^{\text {ns }}$ & $0,0004^{\text {ns }}$ & $0,10^{\text {ns }}$ \\
Fat X Adi & 1 & $963,97^{* *}$ & $10,85^{* *}$ & $1.422,22^{* *}$ & $718,83^{* *}$ & $2.069,38^{* *}$ & $378,12^{* *}$ & $0,84^{\text {ns }}$ & $0,0028^{\text {ns }}$ & $0,56^{* *}$ \\
Resíduo & 24 & 13,13 & 0,25 & 84,25 & 4,08 & 10,13 & 13,00 & 0,34 & 0,0010 & 0,06 \\
\hline CV (\%) & 10,85 & 6,49 & 19,44 & 4,38 & 6,59 & 8,77 & 25,62 & 26,56 & 18,11 \\
\hline
\end{tabular}

* = significativo a $5 \%$ pelo teste de $\mathrm{F}$.

$* *=$ significativo a $1 \%$ pelo teste de $\mathrm{F}$.

ns $=$ não-significativo. 
TABELA 4- Médias da altura, diâmetro de caule, matéria seca das folhas, matéria seca do caule, matéria seca das raízes, porcentagem de pegamento da enxertia e teor de N, P e K nas folhas de portaenxertos de abacateiro cultivar 'Quintal' adubados com diferentes doses de fertilizante de liberação lenta e solução nutritiva. Lavras-MG, 2009.

\begin{tabular}{|c|c|c|c|c|c|}
\hline & \multirow[b]{2}{*}{ Fontes } & \multicolumn{4}{|c|}{ Doses $\left(\mathrm{kg} \mathrm{m}^{-3}\right)$} \\
\hline & & 4 & 8 & 16 & 24 \\
\hline \multirow[t]{2}{*}{ Altura } & FLL* & $43,48 a$ & $35,15 \mathrm{a}$ & $34,53 a$ & $33,03 a$ \\
\hline & $\mathrm{SN}^{* *}$ & $41,05 \mathrm{a}$ & $29,05 \mathrm{~b}$ & $19,48 \quad b$ & $16,93 \mathrm{~b}$ \\
\hline \multirow[t]{2}{*}{ Diâmetro } & FLL* & $9,10 \mathrm{a}$ & $8,17 \mathrm{a}$ & $7,60 \mathrm{a}$ & $7,15 \mathrm{a}$ \\
\hline & $\mathrm{SN}^{* *}$ & $9,00 \mathrm{a}$ & $7,95 \mathrm{a}$ & $6,32 \quad b$ & $5,52 \mathrm{~b}$ \\
\hline \multirow[t]{2}{*}{ MS folhas } & FLL* & $61,75 a$ & $63,00 \mathrm{a}$ & $48,25 a$ & $43,00 \mathrm{a}$ \\
\hline & $\mathrm{SN}^{* *}$ & $60,50 \mathrm{a}$ & $48,25 \mathrm{~b}$ & $20,25 \quad b$ & $11,25 \mathrm{~b}$ \\
\hline \multirow[t]{2}{*}{ MS caule } & FLL* & $60,00 \mathrm{a}$ & $63,25 \mathrm{a}$ & $45,75 a$ & $34,75 \mathrm{a}$ \\
\hline & $\mathrm{SN}^{* *}$ & $58,50 \mathrm{a}$ & $63,00 \mathrm{a}$ & $14,75 \mathrm{~b}$ & $7,5 \quad b$ \\
\hline \multirow[t]{2}{*}{ MS raízes } & FLL* & $73,75 a$ & $62,50 \mathrm{a}$ & $52,00 \mathrm{a}$ & $42,50 \mathrm{a}$ \\
\hline & $\mathrm{SN}^{* *}$ & $74,00 \mathrm{a}$ & $41,00 \mathrm{~b}$ & $13,00 \quad \mathrm{~b}$ & $6,25 \mathrm{~b}$ \\
\hline \multirow[t]{2}{*}{$\%$ PEG } & FLL* & $70 a$ & $50 \mathrm{a}$ & $55 \mathrm{a}$ & $45 \mathrm{a}$ \\
\hline & $\mathrm{SN}^{* *}$ & $45 \quad \mathrm{~b}$ & $55 \mathrm{a}$ & $\mathrm{b}$ & $0 \quad \mathrm{~b}$ \\
\hline \multirow[t]{2}{*}{$\% \mathrm{~N}$} & FLL* & $2,045 \mathrm{a}$ & $2,092 \mathrm{a}$ & $2,247 \mathrm{a}$ & $2,377 \mathrm{a}$ \\
\hline & $\mathrm{SN}^{* *}$ & $2,277 \mathrm{a}$ & $2,415 \mathrm{a}$ & $2,612 \mathrm{a}$ & $2,790 \mathrm{a}$ \\
\hline \multirow[t]{2}{*}{$\% \mathrm{P}$} & FLL* & $0,092 \quad b$ & $0,107 \quad b$ & $0,110 \quad b$ & $0,125 \mathrm{~b}$ \\
\hline & $\mathrm{SN}^{* *}$ & $0,112 \mathrm{a}$ & $0,130 \mathrm{a}$ & $0,15 \mathrm{a}$ & $0,175 \mathrm{a}$ \\
\hline \multirow[t]{2}{*}{$\% \mathrm{~K}$} & FLL* & $1,265 \mathrm{a}$ & $1,547 \mathrm{a}$ & $1,565 \mathrm{a}$ & $1,740 \mathrm{a}$ \\
\hline & $\mathrm{SN}^{* *}$ & $1,400 \mathrm{a}$ & $1,572 \mathrm{a}$ & $1,250 \mathrm{a}$ & $1,457 \mathrm{a}$ \\
\hline
\end{tabular}

Médias seguidas de letras diferentes na coluna diferem entre si, pelo teste do F, ao nível de significância de 5\%.

*Fertilizante de liberação lenta

**Solução nutritiva

TABELA 5- Contrastes entre os efeitos dos tratamentos para as características altura de planta, diâmetro do caule, porcentagem de pegamento da enxertia, matéria seca das folhas, raízes e caule e teor de N, P e K nas folhas de porta-enxertos de abacateiro cultivar Quintal. Lavras-MG, 2009.

\begin{tabular}{lcc}
\hline Contrastes ${ }^{(1)}$ & GL & Quadrados Médios \\
\hline Controle $v$ s. Adubados 1 & 1 & $963,97^{* *}$ \\
Controle $v s$. Adubados 2 & 1 & $10,85^{* *}$ \\
Controle $v s$. Adubados 3 & 1 & $422,22^{* *}$ \\
Controle $v$ s. Adubados 4 & 1 & $718,83^{* *}$ \\
Controle $v s$. Adubados 5 & 1 & $2.069,38^{* *}$ \\
Controle $v s$. Adubados 6 & 1 & $378,12^{* *}$ \\
Controle $v s$. Adubados 7 & 1 & $0,84^{\mathrm{ns}}$ \\
Controle $v s$. Adubados 8 & 1 & $0,00^{\mathrm{ns}}$ \\
Controle $v s$. Adubados 9 & 1 & $0,56^{\mathrm{ns}}$ \\
\hline
\end{tabular}

\footnotetext{
${ }^{(1)}$ Codificação para contrastes: 1- altura de planta; 2- diâmetro do caule; 3- \% de pegamento da enxertia; 4- MS folhas; 5- MS raiz; 6- MS caule; 7- teor de N; 8- teor de P e 9- teor de K.

** = significativo a $1 \%$ pelo teste de $\mathrm{F}$.

ns $=$ não-significativo
} 


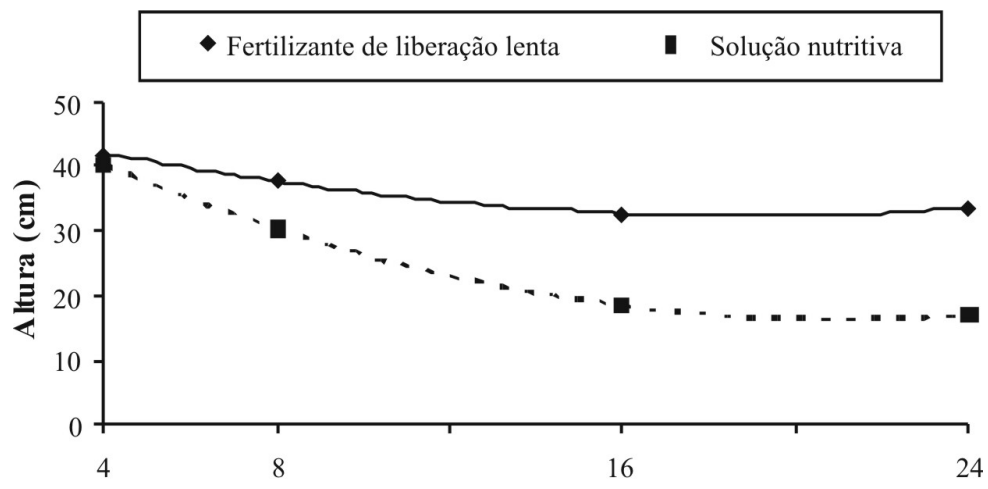

Doses de fertilizante de liberação lenta e solução nutritiva

$$
\left(\mathrm{kg} \mathrm{m}^{-3}\right)
$$

Fertilizante de liberação lenta

$$
\begin{array}{ll}
\hat{Y}=47,976759-1,632483 x+0,042935 x^{2} & R^{2}=83,16 \% \\
\hat{Y}=52,827764-3,457294 x+0,082202 x^{2} & R^{2}=99,06 \%
\end{array}
$$

FIGURA 1- Altura de porta-enxertos de abacateiro cultivar Quintal, adubados com fertilizante de liberação lenta e solução nutritiva. Lavras-MG, 2009.

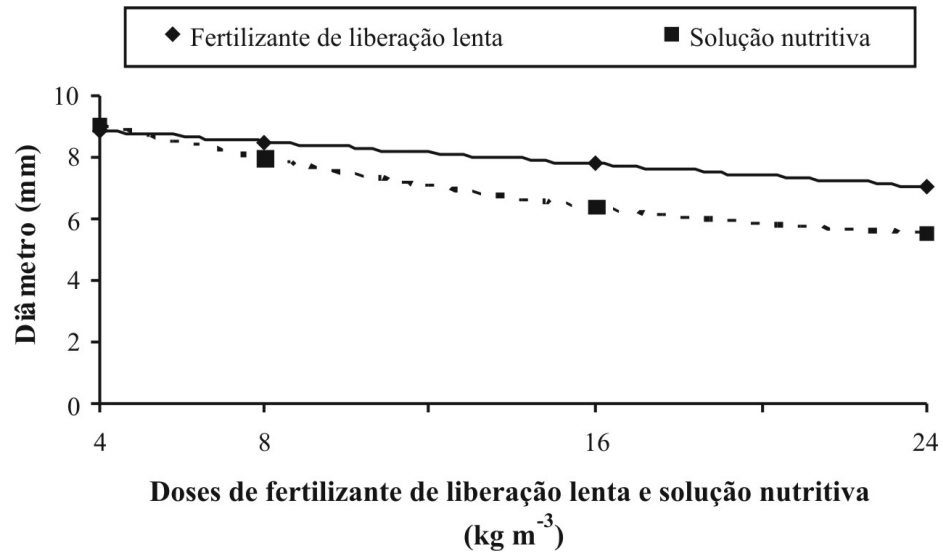

Fertilizante de liberação lenta $\quad \hat{Y}=9,180932-0,090360 x \quad R^{2}=90,77 \%$

Solução nutritiva $\hat{Y}=10,287312-0,343004 x+0,006016 x^{2} \quad R^{2}=96,60 \%$

FIGURA 2- Diâmetro do caule de porta-enxertos de abacateiro cultivar Quintal, adubados com fertilizante de liberação lenta e solução nutritiva. Lavras-MG, 2009. 


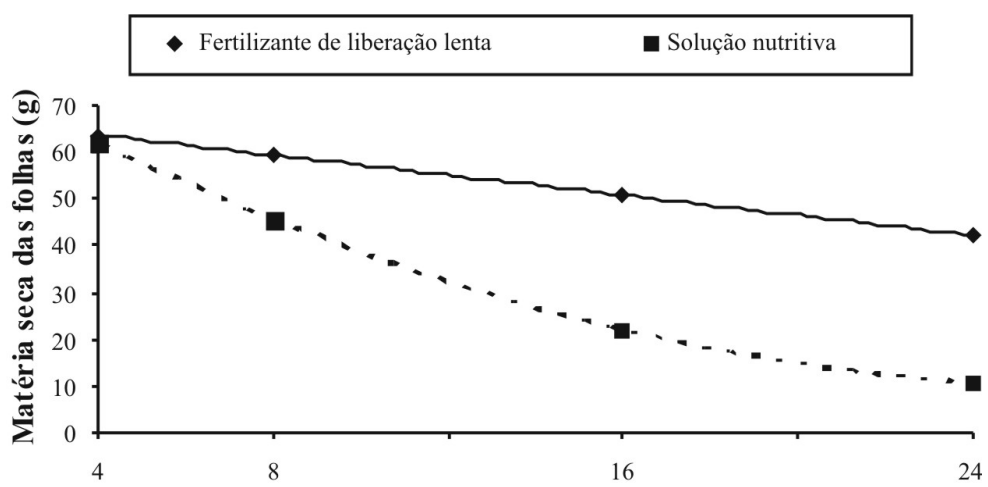

Doses de fertilizante de liberação lenta e solução nutritiva $\left(\mathrm{kg} \mathrm{m}^{-3}\right)$

Fertilizante de liberação lenta $\quad \hat{\mathrm{Y}}=67,936441-1,072034 \mathrm{x} \quad \mathrm{R}^{2}=91,90 \%$

Solução nutritiva $\quad \hat{Y}=81,335427-5,233982 x+0,095477 x^{2} \quad R^{2}=99,21 \%$

FIGURA 3- Matéria seca das folhas de porta-enxertos de abacateiro cultivar Quintal, adubados com fertilizante de liberação lenta e solução nutritiva. Lavras-MG, 2009.

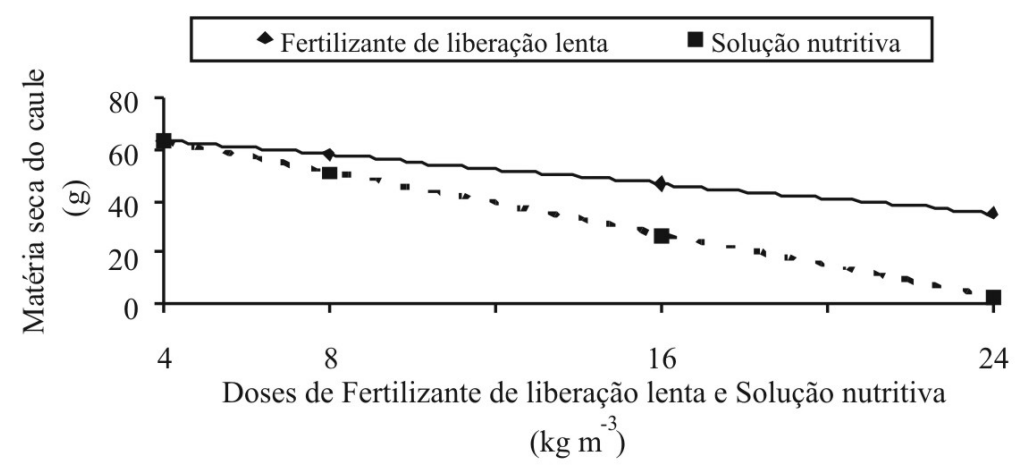

Fertilizante de liberação lenta $\hat{Y}=69,487288-1,426907 x \quad R^{2}=91,93 \%$

Solução nutritiva $\hat{Y}=75,309322-3,028602 x \quad R^{2}=86,62 \%$

FIGURA 4- Matéria seca do caule de porta-enxertos de abacateiro cultivar Quintal, adubados com fertilizante de liberação lenta e solução nutritiva. Lavras-MG, 2009. 


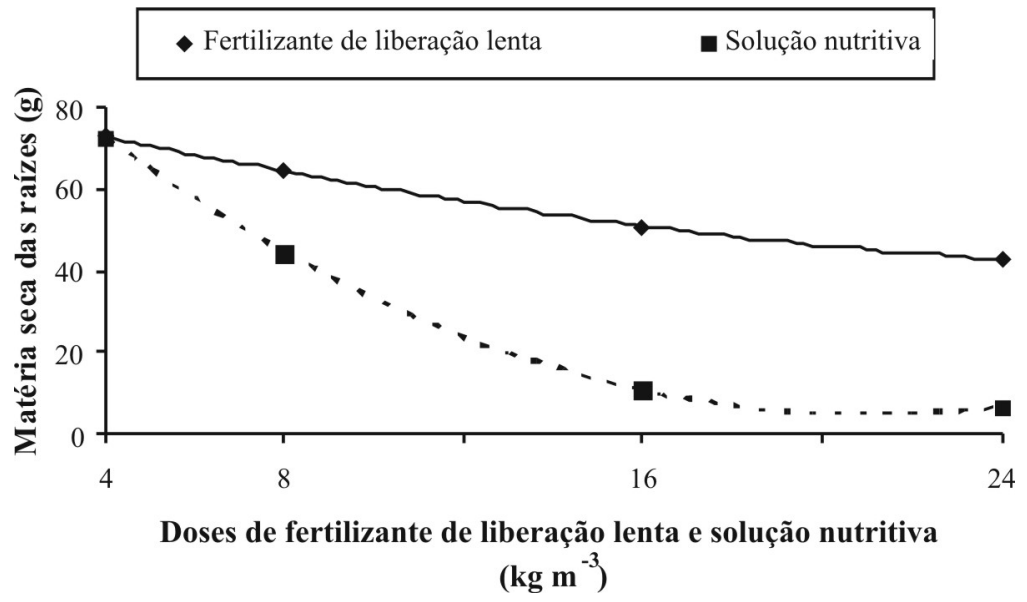

Fertilizante de liberação lenta $\quad \hat{Y}=82,819095-2,658920 x+0,041379 x^{2} \quad R^{2}=99,07 \%$

Solução nutritiva $\hat{Y}=107,545226-9,757145 x+0,231843 x^{2} \quad R^{2}=99,32 \%$

FIGURA 5- Matéria seca das raízes de porta-enxertos de abacateiro cultivar Quintal, adubados com fertilizante de liberação lenta e solução nutritiva. Lavras-MG, 2009.

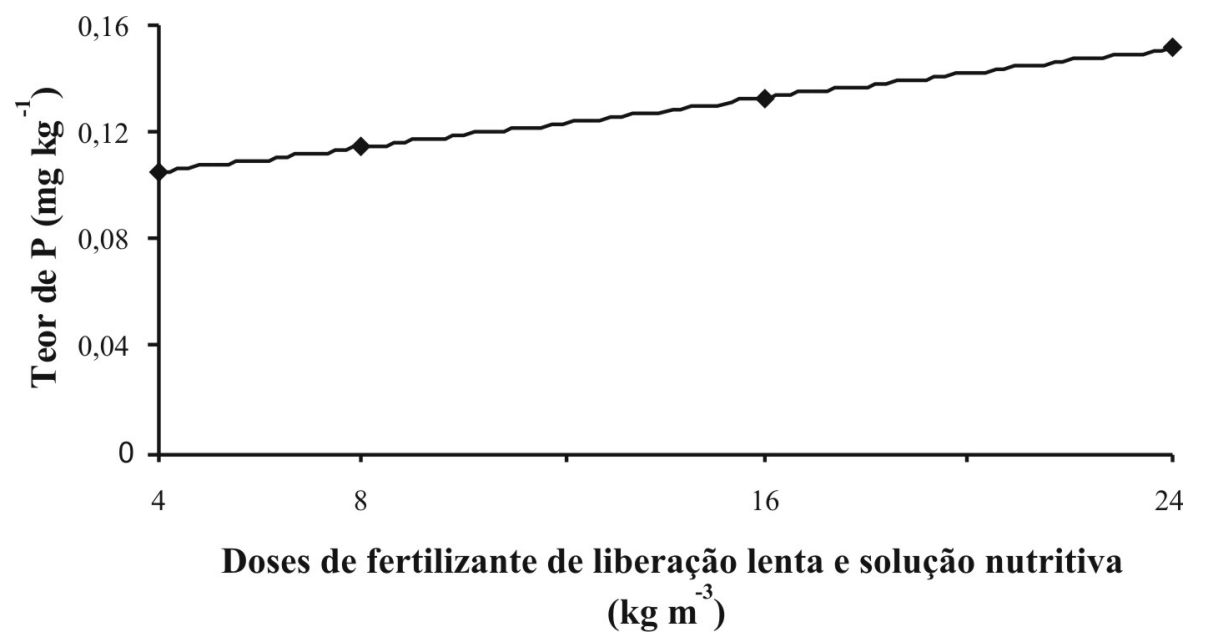

$\hat{\mathrm{Y}}=0,095741+0,002298 \mathrm{x} \quad \mathrm{R} 2=97,23 \%$.

FIGURA 6- Teor de fósforo nas folhas de porta-enxertos de abacateiro cultivar 'Quintal', adubados com fertilizante de liberação lenta e solução nutritiva. Lavras-MG, 2009. 


\section{CONCLUSÕES}

1-O uso de fertilizante de liberação lenta promove maior crescimento e desenvolvimento dos porta-enxertos de abacateiro cultivar 'Quintal' comparado à solução nutritiva.

2-Doses acima de $4 \mathrm{~kg} \mathrm{~m}^{-3}$ tanto de fertilizante de liberação lenta quanto de solução nutritiva não produzem efeito positivo na formação de portaenxertos de abacateiro 'Quintal'.

3-É possível a produção de porta-enxertos de abacateiro sem fertilização.

4-A não inclusão de doses menores que $4 \mathrm{~kg} \mathrm{~m}^{-3}$ não permite estimar a eventual dose ótima para o melhor desenvolvimento dos porta-enxertos.

\section{REFERÊNCIAS}

AGRIANUAL 2010: anuário da agricultura brasileira. São Paulo: FNP Consultoria \& AgroInformativos, 2010. p. 136-140.

ALMEIDA, T. R. P.; SAMPAIO, A. C. Propagação do abacateiro. In: LEONEL, S.; SAMPAIO, A. C. Abacate: aspectos técnicos da produção. São Paulo: Cultura Acadêmica Editora, 2008. p. 65-73.

BRACHTVOGEL, E. L.; MALAVASI, U. C. Volume do recipiente, adubação e sua forma de mistura ao substrato no crescimento inicial de Peltophorum dubium (Sprengel) Taubert em viveiro. Revista Árvore, Viçosa, MG, v.34, n.2, p.223-232, 2010.

BRONDANI, G. E.; SILVA, A. J. C.; REGO, S. S.; GRISI, F. A.; NOGUEIRA, A. C.; WENDLING, I.; ARAUJO, M. A. Fertilização de liberação controlada no crescimento inicial de angico-branco. Scientia Agraria, Piracicaba, v. 9, n. 2, p. 167-176, 2008.

CAVALCANTI, P. P. Experimental designs: um pacote R para análise de experimentos. 2010. $90 \mathrm{f}$. Monografia (Trabalho de Conclusão de Curso Graduação em Biotecnologia) - Universidade Federal de Alfenas, Alfenas, 2010.

COMETTI, N. N.; FURLANI, P. R.; RUIZ, H. A.; FERNANDES FILHO, E. I. Soluções nutritivas: formulações e aplicações. In: FERNANDES, M. S. (Ed.). Nutrição mineral de plantas. Viçosa: Sociedade Brasileira de Ciência do Solo, 2006. p. 88-114.

CFSEMG. Comissão de Fertilidade do Solo do Estado de Minas Gerais. Recomendações para o uso de corretivos e fertilizantes em Minas Gerais: $5^{\text {a }}$ aproximação. Viçosa, 1999. 359 p.
EMBRAPA. Empresa Brasileira de Pesquisa Agropecuária. Sistema brasileiro de classificação de solos. Rio de Janeiro: Centro Nacional de Pesquisa de Solos, 1999. 412 p.

FOOD AND AGRICULTURE ORGANIZATION. Informations. Disponível em: <http://www.fao. org>. Acesso em: 25 abr. 2010.

MALAVOLTA, E.; VITTI, G. C.; OLIVEIRA, S. A. Avaliação do estado nutricional das plantas: princípios e aplicações. 2. ed. Piracicaba: Potafós, 1997. 319p.

MENDONÇA, V.; ABREU, N. A. R.; SOUZA, H. A.; TEIXEIRA, G. A.; HAFLE, O. M.; RAMOS, J. D. Diferentes ambientes e Osmocote ${ }^{\circledR}$ na produção de mudas de tamarindeiro (Tamarindus indica). Ciência e Agrotecnologia, Lavras, v. 32, n. 2, p. 391-397, 2008.

MENDONÇA, V.; TOSTA, M. S.; MACHADO, J. R.; JÚNIOR, S. A. R. G.; TOSTA, J. S.; BISCARO, G. A. Fertilizante de liberação lenta na formação de mudas de maracujazeiro- 'amarelo'. Ciência e Agrotecnologia, Lavras, v. 31, n. 2, p. 344-348, 2007.

NOMURA, E. S.; LIMA, J. D.; RODRIGUES, D. S.; GARCIA, V. A.; FUZITANI, E. J. Influência do substrato e do tipo de fertilizante na aclimatação de mudas de bananeira 'prata-anã'. Ciência e Agrotecnologia, Lavras, v. 33, n. 3, p. 773-779, 2009.

OLIVEIRA, I. V. de M.; CAVALCANTE, I. H. L.; FRANCO, D., MARTINS, A. B. G. Influência da época do ano no sucesso da enxertia nas variedades de abacateiro Hass e Fortuna. Revista Brasileira de Fruticultura, Jaboticabal, v. 30, n. 4, p.11621166, 2008.

PEREIRA, W. E.; LIMA, S. F. de; PAULA, L. B. de; ALVAREZ, V. H. Crescimento e composição mineral de mudas de maracujazeiro em função de doses de Osmocote ${ }^{\circledR}$ em dois tipos de substratos. Revista Ceres, Viçosa, $M G$, v. 47, n. 271, p. 311-324, 2000.

SERRANO, L. A. L.; CATTANEO, L. F.; FERREGUETTI, G. A. Adubo de liberação lenta na produção de mudas de mamoeiro. Revista Brasileira de Fruticultura, Jaboticabal, 2010. Disponível em: $\leq$ http://www.scielo.br/scielo.php?script=sci arttext\&pid=S0100-29452010005000084\&lng $=\overline{p t}$ $\& n r m=$ iso $>$. Acesso em: 15 set. 2010.

SILVA, A. Q.; SILVA, H.; MALAVOLTA, E. Composição mineral de frutos de abacateiro (Persea americana Mill) na colheita. Agropecuária Técnica, Areia, v. 1, n. 1, p. 1-6, 1980. 